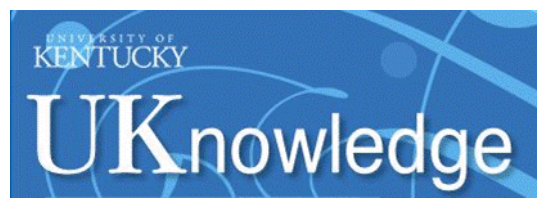

University of Kentucky

UKnowledge

$10-2015$

\title{
Ensuring Access to Oral Health Care for Children: School-Based Care by Dental Therapists - A Commentary
}

\author{
David A. Nash \\ University of Kentucky, danash@uky.edu \\ Kavita R. Mathu-Muju \\ University of British Columbia, Canada \\ Jay W. Friedman \\ Public Health Dental Consultant
}

Follow this and additional works at: https://uknowledge.uky.edu/ohs_facpub

Part of the Dentistry Commons

Right click to open a feedback form in a new tab to let us know how this document benefits you.

\section{Repository Citation}

Nash, David A.; Mathu-Muju, Kavita R.; and Friedman, Jay W., "Ensuring Access to Oral Health Care for Children: School-Based Care by Dental Therapists - A Commentary" (2015). Oral Health Science Faculty Publications. 9.

https://uknowledge.uky.edu/ohs_facpub/9

This Commentary is brought to you for free and open access by the Oral Health Science at UKnowledge. It has been accepted for inclusion in Oral Health Science Faculty Publications by an authorized administrator of UKnowledge. For more information, please contact UKnowledge@lsv.uky.edu. 


\section{Ensuring Access to Oral Health Care for Children: School-Based Care by Dental Therapists - A Commentary}

\section{Digital Object Identifier (DOI)}

http://dx.doi.org/10.1111/josh.12297

\section{Notes/Citation Information}

Published in the Journal of School Health, v. 85, no. 10, p. 659-662.

(C) 2015, American School Health Association

This is the peer reviewed version of the following article: Nash, D. A., Mathu-Muju, K. R. and Friedman, J. W. (2015), Ensuring Access to Oral Health Care for Children: School-Based Care by Dental Therapists - A Commentary. Journal of School Health, 85: 659-662, which has been published in final form at http://dx.doi.org/10.1111/josh.12297. This article may be used for non-commercial purposes in accordance with Wiley Terms and Conditions for Self-Archiving. 
This is the peer reviewed version of the following article: Nash, D. A., Mathu-Muju, K. R. and Friedman, J. W. (2015), Ensuring Access to Oral Health Care for Children: School-Based Care by Dental Therapists - A Commentary. Journal of School Health, 85: 659-662, which has been published in final form at http://dx.doi.org/10.1111/josh.12297. This article may be used for non-commercial purposes in accordance with Wiley Terms and Conditions for Self-Archiving. 


\title{
ENSURING ACCESS TO ORAL HEALTH CARE FOR CHILDREN: SCHOOL-BASED CARE BY DENTAL THERAPISTS
}

\author{
David A. Nash, D.M.D., M.S., Ed.D. (Corresponding Author) \\ William R. Willard Professor of Dental Education \\ Professor of Pediatric Dentistry \\ College of Dentistry \\ University of Kentucky \\ Lexington, Kentucky 40536-0297 \\ danash@email.uky.edu \\ Telephone: 859/323-2026
}

Kavita R. Mathu-Muju, D.M.D., M.P.H.

Assistant Professor of Pediatric Dentistry

Faculty of Dentistry

University of British Columbia

Vancouver, British Columbia, Canada

kmmuju@dentistry.ubc.ca

Telephone: 604/822-3316

Jay W. Friedman, D.D.S., M.P.H.

Public Health Dental Consultant

Los Angeles, California

drjfriedman@sbcglobal.net

Telephone: 310/838-8157 


\section{ENSURING ACCESS TO ORAL HEALTH CARE FOR CHILDREN: SCHOOL-BASED CARE BY DENTAL THERAPISTS}

\section{INTRODUCTION}

The oral health of children is critically important to their overall health and well-

being. Unfortunately, a crisis exists in the oral health of America's children; an epidemic of debilitating dental disease. Furthermore, significant barriers exist for providing all children preventive and rehabilitative care. Other nations of the world have experienced success in both reducing levels of tooth decay in children and also treating dental disease by utilizing dental therapists, clinicians with a "limited scope of practice" in caring for children. International evidence indicates that dental therapists practicing in schools improve access to care, providing safe, quality care, with oral health outcomes better than those in the United States; and they do so more economically. This article will document the problem of dental disease and lack of access to oral health care for children in the United States, suggesting the advantages of adopting a school-based model of care utilizing dental therapists.

\section{CHILDREN'S ORAL HEALTH STATUS}

Tooth decay is our nation's most common childhood disease. It affects approximately $60 \%$ of America's children aged 5-17 years. ${ }^{1}$ Dental care is the most prevalent unmet health need among children. ${ }^{2}$ Eighty percent of dental disease is found in $20 \%-25 \%$ of children — approximately 18 million children — and these children are primarily from minority populations and economically disadvantaged families. ${ }^{3}$ Children lose 52 million 
hours of school time each year because of dental problems. ${ }^{4}$ Children with toothaches are almost 4 times more likely to have a low grade-point average. Poor children experience nearly 12 times as many restricted-activity days because of dental disease as do children from economically advantaged families. ${ }^{5}$ Parents miss 2.5 days of work annually because of their children's dental problems. ${ }^{6}$

\section{BARRIERS TO CHILDREN ACCESSING ORAL HEALTH CARE}

Multiple obstacles to obtaining dental care have been identified for children. ${ }^{7-10}$ Barriers in the professional dental workforce play a significant role in impeding children's ability to access care. Problems include inadequate numbers of dentists, their geographic distribution, education, and failure to accept children with public insurance in their practices.

In 2011, Medicaid and the Children's Health Insurance (CHIP) programs served 43.5 million children. ${ }^{11}$ Thus, the majority of America's children (58\%) were covered with public insurance. This number will rise as a result of the expansion of public insurance with the Affordable Care Act. Yet, few dentists treat publicly-insured children. A 2001 study found that approximately $25 \%$ of dentists received some payment from Medicaid during a given year; however, less than $10 \%$ received $\$ 10,000$ or more, reflecting how few children with public insurance received regular, comprehensive oral health care. ${ }^{12}$

Socio-cultural and economic issues such as transportation, distances to travel for care, work commitments, lack of child care for siblings, out of pocket expenses, and the health literacy of parents are also major barriers for children receiving dental care. Additionally, the stressors of living at or near a level of poverty can reduce dental care to a lower 
family priority. Even were there no social determinants impeding care for children, the dearth of dentists available and willing to treat children with public insurance creates a virtually insurmountable barrier.

\section{THE INTERNATIONAL MODEL OF DENTAL THERAPISTS CARING FOR CHILDREN IN SCHOOL-BASED PROGRAMS.}

In 1921, New Zealand developed a two academic year program to train high school

graduates to become school dental nurses. ${ }^{13}$ These school dental nurses (known as dental therapists since the 1980s) were assigned to school-based dental clinics, eventually providing access to care for the entire New Zealand elementary school population. ${ }^{14-15}$

This model has spread to 54 other countries. ${ }^{16}$ The school-based programs in New Zealand, Hong Kong, Singapore, Malaysia, and formerly in Saskatchewan, Canada are noteworthy in their achievements with school-based care by dental therapists.

In New Zealand there are approximately 600 dental therapists caring for the country's 850,000 children. ${ }^{17}$ Ninety-eight percent of school age children and $60 \%$ of preschool children are provided preventive and rehabilitative dental care annually by dental therapists assigned to dental clinics in New Zealand's elementary and middle schools. A recent report on the oral health of New Zealand's school children documented that $52 \%$ of school children had not experienced tooth decay, and of those who had, over $80 \%$ had been treated. ${ }^{17}$ The average cost of care for the New Zealand School Dental Service in 2011 was $\$ 99 /$ child (U.S.). ${ }^{18}$

Malaysia was the first country to follow New Zealand's lead in establishing a schoolbased dental service. The program resulted in a sharp decline in tooth decay and a 
corresponding increase in treated teeth. A recent study indicated that $97 \%$ of elementary and $91 \%$ of secondary school children had been rendered "orally fit." 19

When Singapore's School Dental Service began in 1946 it was determined that 98\% of children required dental treatment. ${ }^{20}$ A 2009 study found that $89-96 \%$ of the children were "dentally fit." 21 This result was attributed to the role of dental therapists in the School Dental Service. ${ }^{22}$

Hong Kong established a school-based dental service with dental therapists in 1981, resulting in improved access to care and a decline in tooth decay for children. ${ }^{23}$ By 2011 , the participation rate of primary school children was $95 \% .{ }^{24}$ In the most recent study conducted, $62 \%$ of the children aged 12 had never had a cavity; the average number of decayed teeth was less than one; and essentially all of the teeth that had become decayed had been treated. ${ }^{25}$ The estimated annual cost of care in the School Dental Care Service is \$78/child (U.S.) (E.C.M. Lo, personal communication, August, 2012.)

Saskatchewan, Canada instituted a province-wide school-based program staffed by dental therapists in $1974 .{ }^{26}$ After only six years, almost $90 \%$ of the children had all of their treatment needs completed during the school year. ${ }^{27}$ When the program closed in 1988 , as a result of pressure from the province's dentists and the election of a conservative government, the decay prevalence for six year old children had dropped from 6 teeth to only 1 tooth, with essentially all decayed teeth being treated. ${ }^{28}$ The decline in tooth decay coincided with the increased attention given to preventive procedures. The annual cost of care for Saskatchewan's program was recently estimated in current dollars to have been $\$ 176.25 /$ child (U.S.). ${ }^{29}$ 


\section{SCHOOL-BASED HEALTH CARE IN THE UNITED STATES}

Children require high quality, culturally competent, and comprehensive health care. The school setting is a sensible and appropriate place to deliver health care because schools are where children are accessible. School-based health centers (SBHC) reduce health inequities and improve health outcomes for underserved youth. ${ }^{30}$ As one academic pediatrician expressed it, "School-based health centers are the best model of health care in this country for at-risk populations...[they] increase access to health care, eliminate barriers and improve health outcomes for essentially every patient enrolled." ${ }^{31}$

The United States has a long tradition of school-based health services beginning in 1902 with the first nurse assigned to a public school in New York City. ${ }^{32}$ The modern school-based health center initiative, established in the 1970s, provides care by a multidisciplinary team of health workers. Today there are nearly 2,000 school-based health centers serving 2 million children in 46 states and the District of Columbia. ${ }^{30}$

While there are a number of benefits to providing health care to children in a school setting, the primary one is the ability to meet the unmet health care needs in a setting where children are located, thus ensuring access to needed care. School-based care also provides support to parents, permitting them to remain at work, or at home caring for others, while their children's health care needs are being addressed. Both of these advantages are particularly supportive of low income families for whom public insurance covers the provision of care. In fact, SBHCs are predominately located in schools that have large ethnic, minority, and poor populations, which historically have experienced disparities in health care access, including dental care. These centers are increasingly identified as medical homes. The dental home concept should become an integral 
component of SBHCs to ensure access to oral health care for children. While a majority of SBHCs provide some dental services, these are primarily oral health education (84\%) and dental screenings (57\%). A smaller percentage provides dental examinations (20\%), and dental sealants (25\%). Very few (10\%) are equipped to provide therapeutic clinical care such as provided internationally by dental therapists. Only $12 \%$ report having a dental professional on staff. ${ }^{30}$

\section{INTRODUCING DENTAL THERAPISTS IN THE UNITED STATES}

Because of the prevalence of severe dental disease among Alaska Native children and the chronic shortage of dentists willing to work in remote tribal villages, the Alaska Native Tribal Health Consortium, with the support of the Indian Health Service, sent six Alaska Natives to the University of Otago, New Zealand's national dental school, to be trained as dental therapists in 2003. Upon completing the two-year program, they returned to Alaska to practice in 2005 and serve the Alaska Native population living in remote communities. ${ }^{33,34}$

In 2010, an independent assessment of the performance of Alaska's dental therapists concluded dental therapists were "performing well and operating safely and appropriately within their defined scope of practice; were technically competent to perform these procedures;" and patients were "very satisfied with the care received." ${ }^{35}$ Dental therapists are now being trained in Alaska in cooperation with the physician's assistant program of the School of Medicine at the University of Washington. ${ }^{36}$

In 2009, Minnesota passed legislation authorizing the practice of dental therapists.

Subsequently, two training programs were established in the state. ${ }^{37}$ Restrictions were adopted to ensure dental therapists practice in settings that serve low income, uninsured 
and underserved individuals.

The major objection to the introduction of dental therapists in the United States is the belief by many dentists that dental therapists are inadequately trained and provide substandard care. ${ }^{38,39}$ The successful introduction of dental therapists in the workforce of over 50 countries throughout the world, and more recently to the workforce in Alaska and Minnesota provides evidence-based repudiation of this claim. The American Association of Public Health Dentistry and the American Public Health Association have endorsed the practice of dental therapists. ${ }^{40,41}$

\section{DEPLOYING DENTAL THERAPISTS IN SCHOOL-BASED HEALTH}

\section{CENTERS}

Deploying dental therapists to provide care for children in school-based programs not only addresses the issue of access to care and an anticipated reduction in existing disparities, it also makes economic sense. According to the Agency for Health Care Research and Quality, spending for dental care for children aged 5-17 receiving at least one dental visit averaged $\$ 677$ per child in $2009 .{ }^{42}$ Only $50 \%$ of children had at least one dental visit that year. The cost of dental care for children in the U.S. far exceeds that of international school-based programs of \$100-200/child/year. If school-based clinics staffed by dental therapists existed in the United States, not only would access to primary dental care be available for essentially all children, versus the approximately one-half of children who annually receive care currently, but the cost of dental care for children would be dramatically reduced. With the majority of America's children now eligible for primary dental care with public monies, it is essential these funds be expended as 
economically as possible in publically funded school-based programs, as is the international tradition.

\section{CONCLUSION}

Many children face major barriers to dental care that have resulted in inadequate access to care with poor oral health outcomes, particularly for economically disadvantaged children. As the economic barriers to care are reduced through expanding coverage by public insurance, the oral health delivery system must also be transformed to address the further barrier of an inaccessible dental workforce. Dental therapists practicing in public, school-based health centers would provide an economical approach to quality preventive and rehabilitative care for children. Leaders in formulating public policy, federal and state lawmakers, and leaders in public health, education, and dentistry have an obligation to promote "best practices" - foremost of which are dental therapists staffing school-based health centers so that all of our children are able to gain the benefits of comprehensive oral health. 


\section{REFERENCES}

1. US Department of Health and Human Services. National call to action to promote oral health: a public-private partnership under the leadership of the Office of the Surgeon General. Rockville (MD): US Department of Health and Human Services, National Institutes of Health, National Institute of Dental and Craniofacial Research; 2003.

2. Newacheck PW, Hughes DC, Hung YY, et al. The unmet health needs of America's children. Pediatr. 2000;05(suppl 3):989-997.

3. Kaste LM, Selwitz RH, Oldakowski RJ, et al. Coronal caries in the primary and permanent dentitions of children and adolescents 1-17 years of age (1988-91): United States. J Dent Res. 1996;75:631-641.

4. Gift HC, Reisine ST, Larach DC. The social impact of dental problems and visits. Am J Public Health. 1992;82(12):1663-1668.

5. General Accounting Office. Oral health: dental disease is a chronic problem among low-income populations. Report GAO/HEHS-00-72. Washington (DC): General Accounting Office; 2000.

6. Seirawan H, Faust S, Mulligan R. The impact of oral health on the academic performance of disadvantaged children. Am J Public Health. 2012;102(9):17291734. 
7. U. S. Department of Health and Human Services. Oral health in America: a report of the surgeon general. Rockville (MD): U.S. Department of Health and Human Services, National Institute of Dental and Craniofacial Research, National Institutes of Health; 2000.

8. Gehshan S, Straw T. Access to oral health services for low-income people: Policy barriers and opportunities for intervention for the Robert Wood Johnson Foundation. Washington (DC): Forum for State Health Policy Leadership/National Council of State Legislatures; 2002.

9. Improving the oral health status of all Americans: roles and responsibilities of academic dental institutions. Washington (DC): American Dental Education Association; 2003.

10. Oral health: factors contributing to low use of dental services by low-income populations. Washington (DC): General Accounting Office; 2000.

11. Department of Health and Human Services. Center for Medicaid and Medicare Services. Connecting kids to coverage national campaign insure care. Washington (DC): [Cited 2013 May 1] Available from: $\underline{w w w . i n s u r e k i d s n o w . g o v ~}$

12. Gehshan S, Hauck P, Scales J. Increasing dentists' participation in Medicaid and SCHIP. Forum for State Health Policy Leadership. National Conference of State Legislatures. Denver and Washington (DC); 2001.

13. Brooking TWH. A history of dentistry in New Zealand. Dunedin: New Zealand Dental Association; 1980.

14. Nash, DA. Developing a pediatric oral health therapist to help address oral health disparities among children. J Dent Educ 2004;68(1):8-20. 
15. Nash, DA. Developing and deploying a new member of the dental team: a pediatric oral health therapist. $J$ Pub Health Dent. 2005;65(1):48-55.

16. Nash DA, Friedman, JW, Mathu-Muju K, et al. A review of the global literature on dental therapists: in the context of the movement to add dental therapists to the oral health workforce in the United States. W. K. Kellogg Foundation. Battle Creek (MI): April 2012. [Cited 2013 May 1] Available from: www.wkkf.org/knowledge-center/resources/2012/04/nash-dental-therapistliterature-review.aspx

17. New Zealand Ministry of Health. Our oral health: key findings of the $2009 \mathrm{New}$ Zealand oral health survey. Wellington, New Zealand: Ministry of Health; 2010.

18. New Zealand Ministry of Health. Internal Data. Wellington: New Zealand Ministry of Health.

19. Malaysia Ministry of Health. Annual Report 2004: Health Management Information System (Oral Health Subsystem). Kuala Lumpur, Malaysia: Ministry of Health; 2004.

20. Singapore Ministry of Health. Dentistry in Singapore 1819-1996. Singapore: Singapore Ministry of Health; 1996.

21. Singapore Health Promotion Board. A-Z of Health; Annual Report, 2008-2009. Singapore: Health Promotion Board; 2009.

22. Singapore Ministry of health. Information sheet of dental therapists in the Singapore Dental Service. Singapore: Singapore Ministry of Health; 2007.

23. Wong SPY Training and utilization of dental therapists in the school dental care service. J Hong Kong Soc Com Med. 1981;12(1):17-20. 
24. Government of Hong Kong. Department of Health. [Cited 2012 August 20] Available from: www.budget.gov.hk/2012/eng/pdf/head037.pdf

25. Hong Kong Department of Health. Oral health survey 2001: Hong Kong, Government Printer; 2002.

26. Lewis MH. Dental care delivery in Saskatchewan, Canada. In: Ingle JII, Blair P, eds. International dental care delivery systems. Cambridge (MA): Ballinger; 1977.

27. Lewis DW. Performance of the Saskatchewan health dental plan, 1974-1980. Toronto, Ontario, Canada: Faculty of Dentistry, University of Toronto; 1981.

28. Saskatchewan Health. Statistical report of the Saskatchewan health dental plan. September 1, 1987 to August 31, 1988. Saskatoon, Saskatchewan, Canada: Saskatchewan Health; 1988.

29. Canadian Center for Policy Alternatives. Putting our money where our mouth is: the future of dental care in Canada. Ottawa, Ontario, Canada: Canadian Center for Policy Alternative; 2011.

30. National Assembly of School-Based Health Care. Washington (DC); [Cited 2013 May 1 \} Available from: www.nasbhc.org

31. Seen Magazine. School-based health care: why it is common sense. Seen Magazine, March 31, 2010. [Cited 2013 My 1] Available from: http://www.seenmagazine.us/articles/article-detail/articleid/582/school-basedhealthcare.aspx 
32. New York City Department of Education. School Based Health Centers. [Cited 2013, May 1] Available from:

http://schools.nyc.gov/Offices/Health/SBHC/SBHC.htm

33. Nash DA, Nagel R. A brief history and current status of a dental therapy initiative in the United States. J Dent Educ. 2005;69(8):857-859.

34. Nash DA, Nagel R. Confronting oral health disparities among American Indian/Alaska Native children: the pediatric oral health therapist. Amer J of Public Health. 2005;95(8):1325-1329.

35. Wettterhall S, Bader JD, Burrus BB, et al. Evaluation of the dental health aide therapist workforce model in Alaska: final report. Research Triangle Park: RTI International; 2010.

36. Anchorage Daily News. Dental therapist training program opens in Alaska. January 16, 2007.

37. Glasrud PE, Ebetson C, Day T, Diercks R. A history of Minnesota's dental therapist legislation: or ... what the heck happened up there? Minneapolis: Minnesota Dental Association; 2009.

38. American Dental Association. House of Delegates Proceedings. ADA Annual Session. Chicago (Il); 2000.

39. To'olo G, Nash DA Mathu-Muju KR, et al. Pediatric dentists' knowledge and opinions about pediatric oral health therapists. Pediatr Dent 2010;32(6):505-512.

40. American Association of Public Health Dentistry. Resolution on the need for formal demonstration projects to improve access to preventive and therapeutic 
oral health services. Springfield (Il) American Public Health Dentistry Association; 2006.

41. American Association of Public Health. Resolution on dental therapists in Alaska, Washington (DC): American Public Health Association; 2006.

42. US Department of Health and Human Services. Medical expenditure panel survey-Table 3. Dental services-Median and mean expenses per person with expenses by source of payment-General dental visits only. Rockville (MD): Agency for Health care Research and Quality; 2009. 